\title{
ADAPTANDO A ENSINANZA AOS TEMPOS DE PANDEMIA: DA PRESENCIALIDADE AO MODELO EDUCATIVO ONLINE
}

\author{
Pardo Carabias, Cristina ${ }^{1}$ \\ ${ }^{1}$ Universidade da Coruña., Departamento de Pedagoxía e Didáctica, \\ Código ORCID: https://orcid.org/0000-0002-2534-3961
}

\section{RESUMO}

A materia obrigatoria de "Deseño, planificación e avaliación de propostas didácticas de Tecnoloxía na Educación Secundaria" pertence ao Máster Universitario en Profesorado de Educación Secundaria Obrigatoria, Bacharelato, Formación Profesional e Ensinanza de Idiomas (Itinerario: Tecnoloxía) da Universidade da Coruña. Neste traballo descríbese a adaptación de dita materia ás medidas promulgadas pola Xunta de Galicia para paliar a terceira onda da pandemia provocada pola COVID-19. Froito destas medidas, a materia tivo que mudar do modelo presencial ao modelo educativo online. A experiencia vivida con este cambio e as principais conclusións ás que se chegou, son descritas neste traballo. Destácase que para realizar as sesións virtuais é necesario re-programar as actividades e 0 horario das mesmas con respecto ás sesións presenciais, debido ás limitacións que algúns alumnos teñen para acceder a internet e á baixa interacción dos estudantes no modelo de ensino virtual. Ademais, a motivación e os resultados acadados no proceso de ensino-aprendizaxe por parte dos alumnos diminuíron con respecto ás sesións presenciais. Polo tanto, con esta experiencia, conclúese que a docencia baseada en clases presenciais ten máis éxito que a ensinanza baseada só en sesións virtuais, aínda que en ambas as dúas ensinanzas se usen metodoloxías activas co alumnado.

PALABRAS CLAVE: pandemia, proceso de ensino-aprendizaxe, ensinanza telemática, virtual. 


\section{CITA RECOMENDADA:}

Pardo Carabias, Cristina (2021): Adaptando a ensinanza aos tempos de pandemia: da presencialidade ao modelo educativo online. En García Naya, J.A. (ed.) (2021). Contextos universitarios transformadores: a nova normalidade académica. Leccións aprendidas e retos de futuro. $V$ Xornadas de Innovación Docente. Cufie. Universidade da Coruña. A Coruña (pág. 273-286)

DOl capítulo: https://doi.org/10.17979/spudc. 9788497498180.273

DOl libro: https://doi.org/10.17979/spudc. 9788497498180

\section{ABSTRACT}

The compulsory subject "Design, planning and evaluation of didactic proposals of Technology in Secondary Education" belongs to the Master's Degree in Compulsory Secondary Education Teachers, Baccalaureate, Vocational Training and Language Teaching (Itinerary: Technology) of the University of A Coruña. The adaptation of this subject to the measures enacted by the Xunta de Galicia to alleviate the fourth wave of the pandemic caused by COVID-19 is described. The main conclusions reached are described in this paper. It is emphasized that in order to carry out the virtual sessions it is necessary to reschedule the activities and their schedule with respect to the face-to-face sessions, due to the limitations that some students have to access the internet and to the low student interaction in the virtual teaching model. In addition, the motivation and results achieved in the teaching-learning process by students decreased with respect to face-to-face sessions. Thus, with this experience, it is concluded that teaching based on face-to-face classes is more successful than teaching based only on virtual sessions, although in both teachings active methodologies are used among the students.

KEY WORDS: pandemic, teaching-learning process, telematic teaching, virtual. 


\section{INTRODUCCIÓN}

Dentro do Máster Universitario en Profesorado de Educación Secundaria Obrigatoria, Bacharelato, Formación Profesional e Ensinanza de Idiomas da Universidade da Coruña (UDC), concretamente no módulo específico do Itinerario de Tecnoloxía, encóntrase a materia obrigatoria de "Deseño, planificación e avaliación de propostas didácticas de Tecnoloxía na Educación Secundaria” ("Deseño" en adiante; Guía docente, curso 2020/2021, (s.f.)). Trátase dunha materia de 4 créditos ECTS (European Credit Transfer System), no que 1 crédito ECTS equivale a 25-30 horas de traballo por parte do alumnado (Servicio Español para la Internalización de la Educación-SEPIE, 2015). 0 principal obxectivo desta materia é que 0 estudantado de Máster sexa capaz de propoñer e elaborar propostas de intervención na aula, transformando o currículo educativo vixente na Comunidade Autónoma de Galicia, en propostas didácticas competenciais para 0 ensino da Tecnoloxía na Educación Secundaria (Guía docente, curso 2020/2021, (s.f.)). Para iso, o alumando do Máster debe aplicar metodoloxías activas, afastándose do modelo tradicional de profesor transmisor de coñecementos, e integrar significativamente as "Tecnoloxías da Información e da Comunicación" (TIC), de xeito que se poda falar de "Tecnoloxías do Aprendizaxe e do Coñecemento" (TAC) e non só de TIC (Enríquez, 2012; Lozano, 2011).

No presente curso 2020/2021, as clases do Máster Universitario en Profesorado, e, por ende, as clases desta materia en particular, adoptaron unha serie de medidas antiCOVID-19 para permitir a súa impartición presencial (Facultade de Ciencias da Educación, 2020). Con todo, isto non evitou que a finais de xaneiro de 2021 se producira unha terceira onda da actual pandemia, polo que as clases mudaron da presencialidade ao modelo educativo online. Neste novo contexto, a materia de "Deseño" tivo que adaptarse á docencia telemática, respectando en todo momento 0 uso de metodoloxías activas de aprendizaxe entre os dezasete alumnos/as de Máster que asistían á mesma. Destacar que por metodoloxías activas enténdense "aqueles métodos, técnicas e estratexias que utiliza o docente para converter o proceso de ensinanza 
en actividades que fomenten a participación activa do estudante e leven ao aprendizaxe" (traducido ao galego de Labrador-Piquer y Andreu, 2008, p. 6).

\section{DESCRICIÓN DA EXPERIENCIA}

No momento en que o Presidente da Xunta de Galicia, Alberto Núñez Feijoo, anunciou as novas medidas antiCOVID-19 a finais de xaneiro de $2021^{17}$, as clases presencias da materia de "Deseño" mudaron ás clases telemáticas. Dado que a UDC conta cun paquete de aplicacións Microsoft Office 365 a disposición do profesorado e do alumnado, o TEAMS foi a aplicación usada para seguir as clases de "Deseño" de xeito online.

A continuación, descríbense varias sesións virtuais realizadas na materia de "Deseño" no curso 2020/2021, durante a terceira onda da pandemia producida pola COVID-19, ademais da súa adaptación a dita modalidade online. Hai que puntualizar que nestas clases mantívose a utilización do Campus Virtual para a subida de recursos e materias para traballar durante a clase, e, por outra banda, para a subida de arquivos polo propio alumnado nas tarefas que se lle propoñían, para proceder así á corrección das mesmas por parte da docente. En canto á metodoloxía e organización das clases, mantívose en liñas xerais a mesma, usando metodoloxías activas para conseguir unha aprendizaxe significativa entre 0 alumando do Máster. A organización das clases descríbese a continuación. A clase comezaba coa resolución de dúbidas e a corrección das tarefas feitas polo alumnado na sesión anterior. Despois, facíase unha breve explicación sobre os contidos a tratar ese día de clase e, logo, 0 alumnado levaba a cabo unha tarefa, normalmente en pequeno grupo, e a entregaba a través do Campus Virtual, para a súa posterior corrección. Hai que resaltar que, dende o comezo da materia, contouse co permiso de todo o alumnado para facer as correccións das distintas tarefas en gran grupo, para que todos os estudantes puidesen aprender o máximo a través dos

\footnotetext{
${ }^{17}$ Rodríguez, U. y Montero, T. (25 de xaneiro de 2021). En directo: reducidas las reuniones a convivientes, cierre total de la hostelería y el comercio no esencial cerrará a las 18 horas. La Voz de Galicia. https://www.lavozdegalicia.es/retransmision/sociedad/2021/01/25/directo-feijoo-anuncia-restricciones-durasgalicia/01071611575141516747590.htm
} 
erros cometidos. Por outra banda, destacar tamén que os pequenos grupos de traballo estaban formados por 4-5 persoas, de distinto sexo e procedentes de carreiras variadas, manténdose os mesmos grupos en todas as tarefas ao longo da materia. Para traballar en pequeno grupo de xeito telemático, habilitáronse equipos de traballo na aplicación TEAMS. A docente responsable da materia pasaba por cada grupo en TEAMS para aclarar as dúbidas. Puntualizar tamén que a tarefa a realizar por cada pequeno grupo de traballo a tiñan que levar a cabo durante a sesión de clase e subila ao final da mesma ao apartado habilitado para tal fin no Campus Virtual, como se facía nas clases presencias.

0 primeiro día de clase online comezou coa aclaración dunha dúbida xurdida nunha pregunta do cuestionario de avaliación inicial de coñecementos previos, sobre electricidade e electrónica, visto na sesión anterior (Figura 1). Dito cuestionario pretendía exemplificar un tipo de actividade a levar a cabo pola figura do docente, dentro das denominadas "actividades inicias de exploración", para amosar as ideas previas e alternativas dos estudantes de Educación Secundaria (Sanmartí, 2002). A dúbida aclarouse mediante unha breve explicación a través de dous pequenos vídeos feitos pola docente responsable da materia, no que se amosaba, con demostracións prácticas, a resposta correcta (Figura 2). 
Cristina Pardo Carabias

4.- Dispoñemos de dúas pilas e unha lámpada conectadas, segundo aparece na figura:

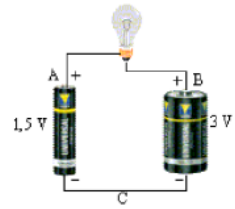

a) Hai diferenza de potencial entre os puntos $A$ e $B$ ?
$\square \mathrm{Si}$
$\square$ Non
$\square$ Non o sei

b) Circula corrente pola lámpada?
$\square \mathrm{si}$
$\square$ Non
$\square$ Non o sei

c) Circula corrente polo cable C?
$\square$ si
$\square$ Non
$\square$ Non o sei

(Haberá moitos estudantes que non relacionen a existencia dunha diferenza de potencial entre dous puntos dun circuito pechado co paso de corrente.)

Figura 1. Pregunta $n^{0} 4$ do cuestionario de avaliación inicial de coñecementos previos. Dita pregunta do cuestionario foi obtida e modificada do traballo de Periago e Bohigas (2005).

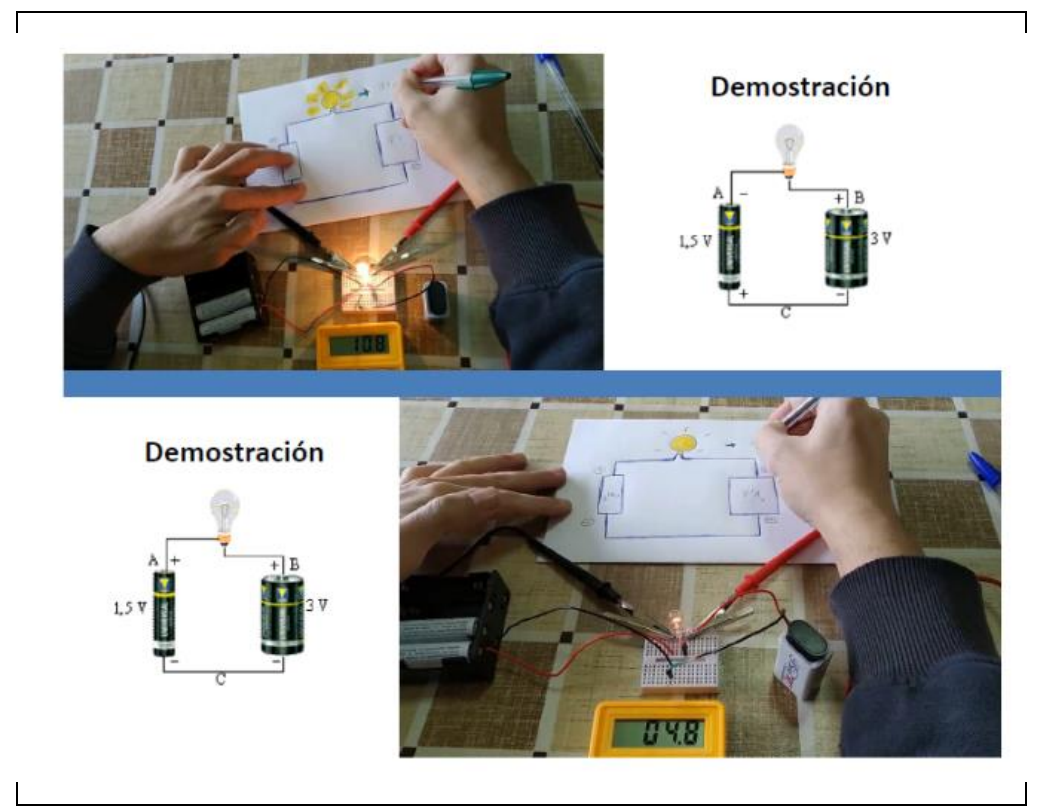

Figura 2. Imaxe dos vídeos creados pola docente responsable da materia de "Deseño" para aclarar as dúbidas xeradas na pregunta $\mathrm{n}^{0} 4$ do cuestionario de avaliación inicial de coñecementos previos amosada na Figura 1. 
Aclarada a dúbida, procedeuse coa corrección da tarefa realizada en pequeno grupo 0 anterior día de clase. Dita tarefa tiña como fin a elaboración de diversas actividades inicias de exploración por parte do alumnado. Unha vez corrixida a tarefa, a docente realizou unha breve explicación sobre as actividades de introdución a novos coñecementos, así como as actividades de reforzo e ampliación (Sanmartí, 2002). Para isto realizouse un estudo de caso. A continuación, procedeuse a traballar nunha tarefa, na que cada pequeno grupo debía deseñar e planificar unha serie de actividades de introdución de novos coñecementos para unha sesión de 50 min. Ditas actividades debían formar parte dunha Unidade Didáctica (UD) para $04^{0}$ curso da ESO, centrada na electrónica analóxica. Ademais, tamén pediuse ao alumando o deseño dunha actividade de reforzo e outra de ampliación para esta mesma UD.

0 seguinte día de clase, é dicir, o segundo día de clase virtual, comezou seguindo a organización habitual das sesións. Deste xeito, aclaráronse as dúbidas xurdidas e procedeuse á corrección da tarefa encomendada aos pequenos grupos de traballo. Dita tarefa estaba centrada na elaboración de actividades de introdución e actividades de reforzo e ampliación. Posteriormente, seguiuse a traballar nas actividades de introdución que, na ensinanza de Tecnoloxía, abarcan tamén sesións prácticas, xa que 0 uso de metodoloxías activas no proceso de Ensino-Aprendizaxe (E-A en adiante), implica tamén a capacitación práctica nas competencias propias da disciplina. Con isto, permítese que o proceso de construción de coñecementos sexa activo e significativo entre o estudantado (Blas Padilla e Jaén Martínez, 2018; Glaser, 1991).

Para estudar as actividades de introdución a novos coñecementos de xeito práctico en Tecnoloxía, levouse a cabo un estudo de caso a través dunha práctica baseada na plataforma Arduino $^{18}$ (Blas Padilla e Jaén Martínez, 2018). Con esta práctica preténdese acercar ao alumnado a certos contidos de "Control e Robótica" que se tratan na materia de Tecnoloxía en $4^{0}$ da ESO (Decreto 86/2015, de 25 de xuño, polo que se establece o currículo da Educación

18 ARDUINO (2021). ARDUINO. https://www.arduino.cc/ 
Secundaria Obrigatoria e do Bacharelato na Comunidade Autónoma de Galicia). Dado que, coas clases telemáticas, o alumnado de Máster non podía acceder in situ ás placas Arduino nin os diferentes compoñentes acompañantes, modificouse a execución desta práctica. Deste xeito, 0 alumnado procedeu soamente á lectura individual do titorial práctico sobre a "montaxe e representación dun intermitente" con Arduino, realizada pola docente para o alumnado de Tecnoloxía de $4^{\circ}$ da ESO. Tras a lectura de dito titorial e aclaradas as dúbidas sobre Arduino, 0 estudantado de Máster puido ver nunha diapositiva o resultado que se acadaría coa práctica se a fixeran in situ (Figura 3). Ademais, fíxose unha demostración a través da cámara web do ordenador da docente sobre dita montaxe e posta en funcionamento.

Posteriormente, nesta sesión procedeuse a seguir traballando coa plataforma Arduino, mais neste caso mediante 0 simulador Tinkercad ${ }^{19}$. No simulador, 0 estudantado de Máster debía montar 0 intermitente explicado no titorial práctico previo, así coma escribir o seu código de funcionamento. Tras isto, continuouse usando o simulador, tamén de xeito individual, mais neste caso, a tarefa baseouse na montaxe e posta en funcionamento dun semáforo con tres luces, para 0 que 0 alumnado debía escribir 0 código de funcionamento correspondente. Para avaliar a tarefa, cada estudante tiña que mandar un pantallazo da montaxe do seu semáforo e do seu código ao lugar habilitado para tal fin no Campus Virtual.

0 terceiro día de clase virtual comezou coa corrección da tarefa individual encomendada ao alumando co simulador Tinkercad. Logo, fíxose unha breve explicación sobre as actividades de estruturación e, por outra banda, as actividades de aplicación. Para motivar ao alumnado e dar máis dinamismo á clase virtual, preparáronse unha serie de vídeos con varios proxectos que poden realizarse co alumando de Tecnoloxía en diferentes niveis da ESO. Entre estes proxectos amosouse a construción dunha maqueta cun semáforo para peóns e dous semáforos para vehículos que circulan por unha estrada de dous sentidos (Figura 4). Con esta

19 Autodesk, Inc. (2021). Autodesk Tinkercad. https://www.tinkercad.com/ 
maqueta 0 alumnado do Máster puido ver os proveitos da ferramenta educativa Arduino para a ensinanza da electrónica e programación na Educación Secundaria.

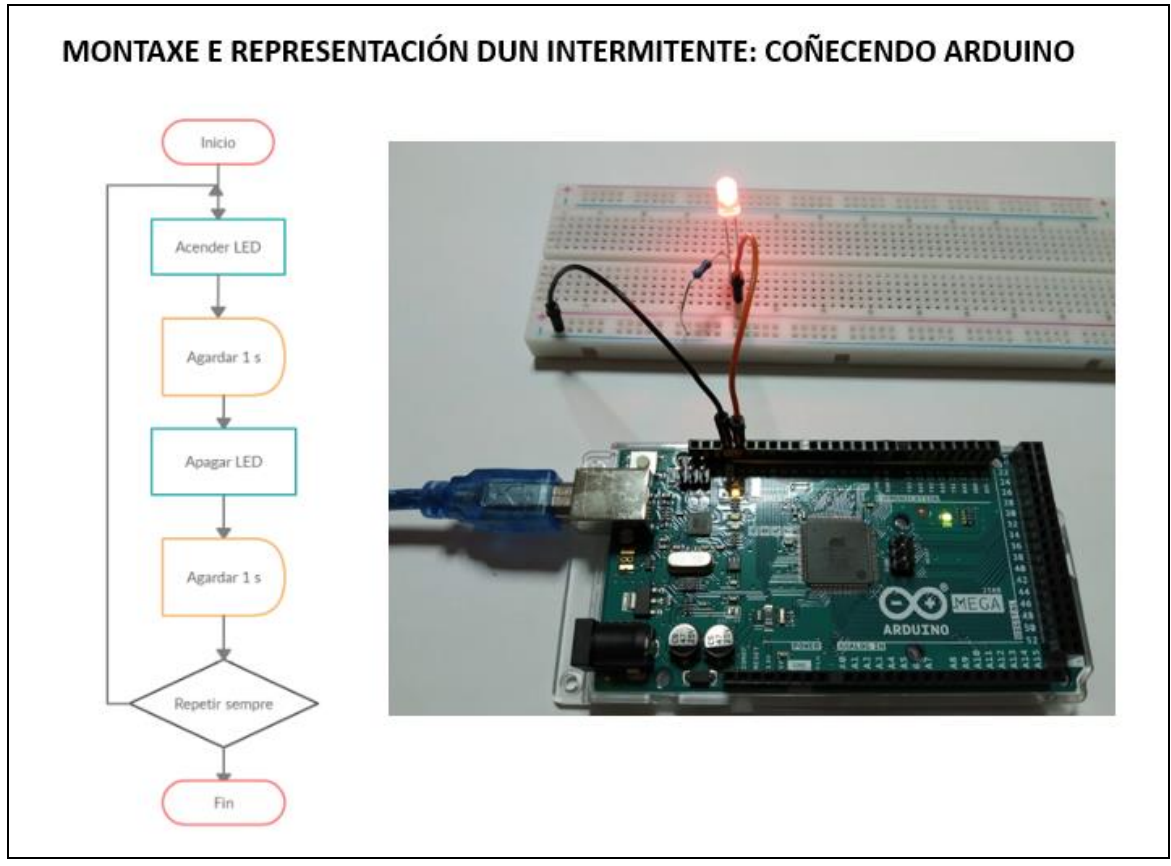

Figura 3. Intermitente en funcionamento.



Figura 4. Imaxe do vídeo realizado pola docente responsable da materia de "Deseño" para amosar a maqueta cun paso de peóns e dous semáforos para automóbiles. 
Ademais da visualización dos vídeos, fíxose unha demostración do funcionamento dos diferentes proxectos a través da cámara web da docente, comentando en gran grupo onde encaixarían mellor dentro dos diferentes cursos da ESO, segundo o currículo especificado no Decreto 86/2015 e o grao de dificultade dos mesmos. Dado os numerosos proxectos que se amosaron (máis de 10 proxectos), xunto aos problemas de conexión a internet xurdidos nesta sesión, a clase rematou sen que 0 alumnado puidese realizar a tarefa en pequeno grupo programada para ese día.

\section{RESULTADOS}

Nesta sección amósanse os principais resultados acadados nas sesións virtuais descritas na sección anterior, realizadas na materia de "Deseño" no curso 2020/2021 durante a terceira onda da pandemia producida pola COVID-19.

Hai que resaltar que todos os alumnos da materia posuían coñecementos básicos sobre 0 uso da aplicación TEAMS, polo que non supuxo un problema a súa utilización. Non obstante, 0 contratempo que xurdiu foi a calidade da conexión a internet, interrompéndose en ocasións pola caída da mesma, como se comenta ao longo desta sección.

Na primeira sesión virtual de clase amosouse unha maior motivación do alumnado co formato online das clases, achacado segundo ao alumnado ao poder estar sen máscara e na súa casa. Esta motivación inicial viuse diminuída a medida que se sucedían máis sesións virtuais, dado que, segundo o propio alumnado, a interacción cos compañeiros/as non se producía tan ben como nas clases presenciais. En canto ao desenvolvemento do primeiro día de clase virtual, a aclaración da dúbida xurdida na pregunta $n^{0} 4$ do cuestionario de avaliación inicial de coñecementos previos sobre electricidade e electrónica, resolveuse con éxito coa visualización dos dous vídeos elaborados pola docente. Nunha situación de docencia presencial levaríase a cabo a demostración en directo, tal e como se fixo nos vídeos. Por outra banda, a realización da tarefa en pequeno grupo dese día alargouse no tempo. Os diferentes grupos tiveron 
problemas á hora de traballar nos equipos de TEAMS, unhas veces por falta de conexión e outras por ter que esperar quenda para a aclaración de dúbidas por parte da docente. Isto fixo que a clase alargárase 15 minutos fora do horario lectivo, tendo que engadirse tamén, como consecuencia, máis tempo na entrega da tarefa no Campus Virtual. Por outra parte, nas dúbidas xurdidas, comprobouse a reiteración das mesmas entre os diferentes equipos de traballo, tomándose medidas neste sentido nas seguintes tarefas a realizar en pequeno grupo.

No segundo día de clase, a corrección da tarefa encomendada aos pequenos grupos, neste caso sobre as actividades de introdución e as actividades de reforzo e ampliación, alargouse no tempo. Tratábase dunha tarefa longa, na que se observaron moitos erros nos arquivos enviados polos diferentes grupos. Deste xeito, a docente decidiu que 0 alumnado, en base aos comentarios e suxerencias realizadas na clase, realizara unha revisión e corrección da tarefa. Para iso, os estudantes contaron con 30 minutos de traballo nos diferentes equipos de TEAMS e habilitouse novamente 0 espazo no Campus Virtual para a súa entrega e posterior avaliación. Despois disto, abordouse a práctica con Arduino.

Dos dezasete alumnos/as da materia de "Deseño", soamente tres coñecían a plataforma Arduino. De feito, un destes tres alumnos, foi montando o intermitente na súa placa Arduino a medida que lía 0 titorial práctico, xa que posuía na súa casa dita placa, así coma o resto dos compoñentes necesarios. Tras a lectura do titorial, entre 0 alumnado que non coñecía Arduino, xurdiu certa preocupación cando pasaron a traballar no simulador Tinkercad. Dita preocupación centrábase na programación do código, xa que non posuían coñecementos sobre programación. A pesar da preocupación inicial, a aprendizaxe do uso da plataforma Arduino en simulador foi rápida, tal e como observaron tamén Candelas Herías et al. (2015) na súa experiencia universitaria. Moitos dos estudantes do Máster manifestaron, ao final da tarefa individual, a súa satisfacción ao conseguir escribir correctamente o código do semáforo de tres luces. 
No terceiro día de clase, a corrección da tarefa individual sobre a montaxe e escritura do código do semáforo de tres luces, fíxose cunha chamada de atención ao alumnado. Detectouse que unha persoa da clase fixera unha busca en Tinkercad sobre o semáforo de tres luces feito por outro usuario deste simulador, e copiara directamente o seu código, facendo plaxio, sen intentar facelo por el mesmo, sen cambiar os requirimentos que se especificaron nesta tarefa (i.e. segundos que debía estar acesas as luces), e sen citar a correspondente referencia. Isto supuxo a avaliación negativa desta tarefa para esa persoa. 0 resto da sesión, segundo 0 alumnado, foi do seu agrado, debido ao gran número de proxectos presentados e comentados, o que lles deu ideas para o seu futuro profesional coma docentes de Educación Secundaria, así como para o período do PRACTICUM, no que tiñan que impartir parte dunha UD elaborada por eles mesmos.

\section{CONCLUSIÓNS}

Nesta sección expóñense as reflexións sobre a experiencia vivida na materia de "Deseño", durante a terceira onda da pandemia provocada pola COVID-19, no curso 2020/2021.

En xeral, os problemas de conexión a internet e a menor interacción do alumnado nas sesións online, provocaron que as actividades e a temporalización das mesmas se viran modificadas respecto á planificación inicial. Por iso, conclúese que nas sesións virtuais requírese reprogramar de novo as actividades e modificar a súa temporalización con respecto ás sesións presencias, deixando, ademais, certo marxe de tempo para suplir os problemas tecnolóxicos que poidan xurdir.

Por outra banda, a pesar da motivación inicial do alumando coas clases virtuais, provocada segundo eles por estar na casa e non levar máscara, esta diminuíu a medida que se sucederon as diferentes sesións. Xunto a isto, produciuse unha diminución da interacción entre 0 alumnado en TEAMS, a pesar de que se seguiron usando metodoloxías activas. Todo ilo en conxunto, levou a que se produciran peores resultados nas tarefas realizadas en pequeno grupo no modelo educativo virtual que as que se fixeron de xeito presencial con este tipo de 
agrupamento. Deste xeito, conclúese que a docencia baseada exclusivamente en sesións virtuais ten menos éxito que a ensinanza baseada en sesións presenciais, obténdose co modelo educativo presencial mellores resultados de aprendizaxe entre os e as estudantes.

\section{REFERENCIAS}

Blas Padilla, D. y Jaén Martínez, A. (2018). Experiencia didáctica con Arduino. El aprendizaje basado en proyectos como metodoloxía de trabajo en el aula de secundaria. Hekademos: revista educativa digital, 25, pp. 73-82. https://dialnet.unirioja.es/servlet/articulo?codigo $=6789674$

Candelas Herías, F.A., García Gómez, G.J., Pomares Baeza, J., Jara Bravo, C.A., Delgado Rodríguez, A., Matero Agulló, C.M., Mira Martínez, D. y Pérez Alepuz, J. (2015). Experiencias sobre el uso de la plataforma Arduino en prácticas de Automatización y Robótica. En Tortosa Ybáñez, M.T., Álvarez Teruel, J.D. y Pellín Buades, N. (Coords.), XIII Jornadas de Redes de Investigación en Docencia Universitaria. Nuevas estrategias organizativas y metodológicas en la formación universitaria para responder a la necesidad de adaptación y cambio (pp. 84-100). España: Universidad de Alicante.

https://rua.ua.es/dspace/bitstream/10045/48815/1/XIII_Jornadas_Redes_07.pdf

Decreto 86/2015, de 25 de xuño, polo que se establece 0 currículo da Educación Secundaria Obrigatoria e do Bacharelato na Comunidade Autónoma de Galicia. Diario Oficial de Galicia. Santiago de Compostela, 29 de xuño de 2015, núm. 120, pp. 25434-27073. https:/www.xunta.gal/dog/Publicados/2015/20150629/AnuncioG0164-2606150002_es.html

Enríquez, S.C. (2012). Luego de las TIC, las TAC. [Archivo PDF]. http://sedici.unlp.edu.ar/bitstream/handle/10915/26514/Documento_completo.luego\%20de \%20las\%20TIC,\%20las\%20TAC\%20(1).pdf?sequence=1\&isAllowed=y

Facultade de Ciencias da Educación (2020). Plan de prevención e hixiene fronte á COVID-19 na Facultade de Ciencias da Educación da Universidade da Coruña para 0 curso 2020/2021. 
[Archivo PDF]. https://www.educacion.udc.es/documentos/covid-19/20-PROTOCOLOFACULTADE-revision-mayo-2021.pdf

Glaser R. (1991) The Maturing of the relationship between the science of learning and cognition and educational practice, Learning and Instruction,1(s), pp. 129-144.

https://www.sciencedirect.com/science/article/abs/pii/0959475291900232?via\%3Dihub

Guía docente, curso 2020/2021. (s.f.). Deseño, planificación e avaliación de propostas didácticas de Tecnoloxía na Educación Secundaria.

https://guiadocente.udc.es/guia_docent/index.php?centre $=652 \&$ ensenyament $=652602 \& a$ ssignatura $=652602222 \&$ fitxa_apartat $=4 \&$ any_academic $=2020 \_21 \& i d i o m a \_a s s i g=$

Labrador-Piquer, M. J., \& Andreu, M. A. (2008). Metodologías activas. Grupo de inno-vación en metodologías activas. Valencia: Universidad politécnica de Valencia. http://www.upv.es/diaal/publicaciones/Andreu-

Labrador12008_Libro\%20Metodologias_Activas.pdf

Lozano, R. (2011). Las TIC/TAC: de las tecnologías de la información y comunicación a las tecnologías del aprendizaje y del conocmiento. Anuario ThinkEPI, (5), 45-47. https://recyt.fecyt.es/index.php/ThinkEPI/article/view/30465

Periago, M.C. y Bohigas, X. (2005). Persistencia de las ideas previas sobre potencial eléctrico, intensidad de corriente y ley de Ohm en los estudiantes de segundo curso de Ingeniería. Revista Electrónica de Investigación Educativa, 7(2), pp. 1-23. https://redie.uabc.mx/redie/article/view/136

Sanmartí, N. (2002b). Organización y secuenciación de las actividades de enseñanza/aprendizaje. En N. Sanmartí, N. (Coord.), Didáctica de las Ciencias de la Educación Secundaria Obligatoria, (pp. 295-328). Madrid: Síntesis.

Servicio Español para la Internalización de la Educación-SEPIE. (2015). Guía del uso del ECTS [Archivo PDF]. https://ec.europa.eu/education/sites/default/files/document-librarydocs/ects-users-guide_es.pdf 